\title{
Perception of a New Prolonged-Release Buprenorphine Formulation in Patients with Opioid Use Disorder: The PREDEPO Study
}

\author{
Francisco Salvador Pascual ${ }^{\mathrm{a}} \quad$ Alvaro Muñoz $^{\mathrm{b}}$ Rodrigo Oraa ${ }^{\mathrm{c}}$ Gerardo Flórez $^{\mathrm{d}}$ \\ Pilar Notario $^{\text {e }}$ Pedro Seijo $^{f}$ Begoña Gonzalvo ${ }^{g}$ Carla Assaf $^{\text {h }}$ Manuel Gómez ${ }^{b}$ \\ Miguel Ángel Casado ${ }^{b}$
}

\begin{abstract}
${ }^{a} G e n e r a l i t a t$ Valenciana, Unidad de Conductas Adictivas, Departament de Sault d'Alcoi, Alcoi, Spain; ${ }^{b}$ Outcomes Research, Pharmacoeconomics \& Outcomes Research Iberia (PORIB), Madrid, Spain; 'Red de Salud Mental, Biocruces Bizkaia Health Research Institute, CSM Ajuriaguerra Adicciones, RSMB, Bilbao, Spain; 'Servizo Galego de Saúde, Unidad de Conductas Adictivas de Ourense, Ourense, Spain; 'Subdirección General de Adicciones, Centro de Atención a las Adicciones de Latina, Madrid, Spain; fDiputación de Cádiz, Centro de Tratamiento Ambulatorio de Adicciones de Villamartín, Cádiz, Spain; ${ }^{9}$ Red Adicciones, Institut Assistència Sanitària, Departament de Salut Centro

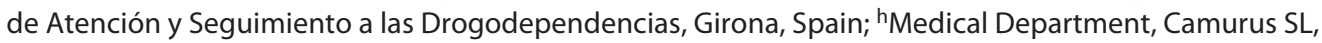

Madrid, Spain
\end{abstract}

\section{Keywords}

Opioid use disorder · Methadone · Buprenorphine/ naloxone $\cdot$ Opioid dependence treatment · Patient perception · Prolonged-release buprenorphine

\begin{abstract}
Aim: The aim of the study was to assess the acceptance of patients with opioid use disorder (OUD) to switching their opioid dependence treatment (ODT) for a prolonged-release buprenorphine (PRB) injection according to their prior ODT (buprenorphine/naloxone [B/N] or methadone). Methods: This was an observational, retrospective/cross-sectional, multicentre study of adult patients diagnosed with OUD on ODT. Data collected from diaries were analysed to know their interest and opinion on PRB. Questions with fixed response options were included, and several Likert scales were used. Results: A total of 98 patients were enrolled (B/N:
\end{abstract}

karger@karger.com www.karger.com/ear

Karger $\stackrel{\text { ' }}{5}$

GOPEN ACCESS
C 2021 The Author(s).

Published by S. Karger AG, Basel

This article is licensed under the Creative Commons Attribution 4.0 International License (CC BY) (http://www.karger.com/Services/ OpenAccessLicense). Usage, derivative works and distribution are permitted provided that proper credit is given to the author and the original publisher.
$50.0 \%$, methadone: $50.0 \%)$. The mean age was $46.9 \pm 8.43$ years and $79.6 \%$ were males. PRB was similarly perceived by both groups in most variables analysed, receiving a mean score of 7.2/10 (B/N: 7.4, methadone: 7.0; $p=0.520)$, and approximately $65 \%$ of patients said they were willing to switch to PRB (B/N: $63.3 \%$, methadone: $65.3 \% ; p=0.833)$. Of these, a higher percentage in the $\mathrm{B} / \mathrm{N}$ group considered that switching would be easy/very easy (B/N: $90.3 \%$, methadone: $46.9 \%$; $p<0.001)$ and that they would start PRB when available (B/N: $64.5 \%$, methadone: $34.3 \% ; p=0.005$ ). More than $90 \%$ would prefer the monthly injection (B/N: $93.6 \%$, methadone: $100 \%$; $p=0.514$ ). One-third of patients in both groups were unsure/ would not switch their ODT to PRB (B/N: $36.7 \%$, methadone: $34.7 \% ; p=0.833)$. The main reason was administration by injection. Conclusion: Two-thirds of patients would switch their treatment for PRB, and most patients on B/N considered that switching would be easy. PRB could be a suitable alternative for OUD management.

(c) 2021 The Author(s)

Published by S. Karger AG, Basel
Correspondence to:

Alvaro Muñoz, amunoz@porib.com 


\section{Introduction}

Opioid use disorder (OUD) is a significant health problem affecting around 27 million people worldwide [1]. In the European Union, the prevalence of high-risk opioid use among adults in 2018 was estimated at $0.4 \%$ of the population, representing 1.3 million users [2]. Although prevalence in European adults is low, OUD is associated with high morbidity and mortality rates. Comorbidities include blood-borne infectious diseases - especially human immunodeficiency virus and hepatitis $\mathrm{C}$ virus (HCV) [3-5] - as well as psychiatric disorders such as depression, anxiety, and dissocial personality disorder [6]. Harmful effects related to use of drugs such as risk of overdose, unemployment, crime, homelessness, or social exclusion, should also be considered [2]. All these factors, combined with the fact that OUD is a chronic disorder characterized by frequent relapses, result in a large number of medical and social problems, as well as a high economic impact for both the individual and society [7].

Methadone (a full mu-opioid agonist) and buprenorphine (a partial agonist) or its combination with naloxone (an antagonist) $(\mathrm{B} / \mathrm{N})$ are the therapeutic options most commonly used as opioid dependence treatment (ODT) for OUD at an international level [2, 8-10]. Many studies have shown that ODTs are effective in the long term [2, 9, 11-13] and are more effective with higher treatment adherence. ODTs are associated with health benefits [13] decreasing the rate of all-cause mortality and overdose [14] and the risk of transmission of blood-borne infectious diseases $[13,15]$. This results in fewer hospitalizations and admissions, a better management of psychiatric diseases [13], and decreased crime rates [16].

These drugs have usually been administered once daily and come in liquid or tablet form [17]. Patients must therefore frequently go to collect the medication, which constitutes a high healthcare burden [18]. Many patients find that the process of collecting the medication frequently and daily dosing is stigmatizing, restricts their freedom, and impairs their quality of life because it makes work, holidays, and participation in other daily activities difficult [19-21]. Treatment non-adherence and discontinuation are therefore common [22].

Poor adherence, along with barriers associated with the existing ODTs, has led to interest and investment in new types of treatments. These include prolonged-release buprenorphine (PRB) formulations - implants or subcutaneous injections - and provide a prolonged release of buprenorphine over weeks or months, depending on the type of formulation. This avoids the need for daily dosing, thus allowing for overcoming the burden of daily treatment for both patients and the healthcare system, and improves patient adherence $[21,23,24]$. These new prolonged-release formulations may offer advantages over current treatments, such as the possibility to start ODT in non-specialized medical care centres; reduce the burden and stigma of treatment; avoid diversion and misuse of buprenorphine or methadone; and provide another treatment option for OUD, increasing therapeutic options to adapt management to patient expectations [25]. The aim of this study was therefore to determine the perception of a new formulation of $\mathrm{PRB}$ injection in patients with OUD, according to their current ODT (methadone or B/N).

\section{Methods}

Study Design

This was an observational, retrospective/cross-sectional, multicentre study. The study was performed in 6 addiction care centres of the Spanish National Health System located in 6 autonomous communities. Data collection (recruitment period) took place between September and October 2020. To avoid bias in collection of information, patients were recruited as they attended the clinic and signed the informed consent form until each treatment group was completed. The PREDEPO study was approved by the Research Ethics Committee of Euskadi (Basque Country, Spain) and was conducted in accordance with the principles of the Declaration of Helsinki regarding medical research in human subjects.

\section{Study Population}

Patients diagnosed with OUD treated with ODT (sublingual $\mathrm{B} / \mathrm{N}$ or oral methadone) and who provided their written consent were recruited. The inclusion criteria were patients older than 18 years diagnosed with OUD according to the Diagnostic and Statistical Manual of Mental Disorders [26], on medically prescribed ODT and whose participation was voluntary. The exclusion criteria were inability of the patient to read and understand the questions of the diary or informed consent or the presence of a psychic dysfunction that could lead to unwillingness or inability to comply with study procedures.

\section{Data Collection}

The materials used for study data collection were a case report form (CRF) and a patient diary, both in paper format. Investigators in each site retrospectively completed the CRF with sociodemographic and clinical data obtained from the clinical histories and electronic medical records of the centre. Patients cross-sectionally completed a patient diary divided into 2 parts. The first part included questions related to patient expectations and their relationship with their ODT (i.e., satisfaction with their current treatment and objectives of their TSO), while the second part included questions to know the interest and opinion of patients on a weekly or monthly PRB subcutaneous injection. Before completing the diary, patients were given information on the route of administration, efficacy, and safety of this new formulation of PRB injection to know their opinion on this product, which was defined as "product X". 
Table 1. Sociodemographic and clinical characteristics

\begin{tabular}{|c|c|c|c|c|}
\hline Variable & Total $(n=98)$ & Methadone $(n=49)$ & $\mathrm{B} / \mathrm{N}(n=49)$ & $p$ value \\
\hline \multicolumn{5}{|l|}{ Age, years } \\
\hline Mean (SD) & $46.9(8.4)$ & $46.7(7.7)$ & $47.0(9.2)$ & 0.873 \\
\hline \multicolumn{5}{|l|}{ Sex, $n(\%)$} \\
\hline Male & 78 (79.6) & $40(81.6)$ & 38 (77.6) & \multirow[t]{2}{*}{0.616} \\
\hline Female & $20(21.4)$ & $9(18.4)$ & $11(22.4)$ & \\
\hline \multicolumn{5}{|l|}{ Stable family situation, $n(\%)$} \\
\hline Has children & $37(37.8)$ & $13(26.5)$ & $24(49.0)$ & 0.022 \\
\hline Stable home situation & $70(71.4)$ & $36(73.5)$ & $34(69.4)$ & 0.655 \\
\hline \multicolumn{5}{|l|}{ Organic disease, $n(\%)^{\#}$} \\
\hline HIV & 19 (19.3) & $9(18.4)$ & $10(20.4)$ & 0.798 \\
\hline $\mathrm{HCV}$ & $12(12.2)$ & $11(22.5)$ & $1(2.0)$ & 0.002 \\
\hline Pulmonary disorder & $9(9.2)$ & $5(10.2)$ & $4(8.2)$ & 1.000 \\
\hline $\mathrm{HBV}$ & $6(6.1)$ & $5(10.2)$ & $1(2.0)$ & 0.111 \\
\hline Heart disease & $1(1.0)$ & $0(0.0)$ & $1(2.0)$ & 1.000 \\
\hline Other & $10(10.2)$ & $4(8.2)$ & $6(12.2)$ & 0.487 \\
\hline \multicolumn{5}{|l|}{ Psychiatric comorbidities, $n(\%)^{\#}$} \\
\hline Personality disorder & $26(26.5)$ & $13(26.5)$ & $13(26.5)$ & 1.000 \\
\hline Major depression & $18(18.4)$ & $6(12.2)$ & $12(24.5)$ & 0.118 \\
\hline Psychosis/schizophrenia & $14(14.3)$ & $5(10.2)$ & $9(18.4)$ & 0.248 \\
\hline ADHD & $5(5.1)$ & $4(8.2)$ & $1(2.0)$ & 0.362 \\
\hline Other & $7(7.1)$ & $4(8.2)$ & $3(6.1)$ & 1.000 \\
\hline \multicolumn{5}{|c|}{ Time since the start of the first ODT, years } \\
\hline Mean (SD) & $13.5(9.0)$ & $16.7(9.3)$ & $10.4(7.6)$ & $<0.001$ \\
\hline \multicolumn{5}{|c|}{ Time since start of current ODT, years } \\
\hline Mean (SD) & $7.3(7.2)$ & $9.7(8.6)$ & $4.6(4.2)$ & $<0.001$ \\
\hline \multicolumn{5}{|l|}{ Current phase of ODT, $n(\%)$} \\
\hline Maintenance & $87(88.8)$ & $45(91.8)$ & $42(85.7)$ & \multirow{2}{*}{0.337} \\
\hline Reduction & $11(11.2)$ & $4(8.2)$ & $7(14.3)$ & \\
\hline \multicolumn{5}{|c|}{ Frequency of medication collection, $n(\%)^{*}$} \\
\hline$<$ Month & $55(57.3)$ & $44(89.8)$ & $11(23.4)$ & \multirow{5}{*}{$<0.001$} \\
\hline Monthly & $25(26.0)$ & $5(10.2)$ & $20(42.6)$ & \\
\hline$>$ Month & $11(11.5)$ & $0(0.0)$ & $11(23.4)$ & \\
\hline Electronic prescription & $5(5.2)$ & $0(0.0)$ & $5(10.6)$ & \\
\hline Missing value & 2 & 0 & 2 & \\
\hline
\end{tabular}

Attributes with $p<0.05$ are shown in bold. ADHD, Attention deficit hyperactivity disorder; $\mathrm{B} / \mathrm{N}$, buprenorphine/ naloxone; HBV, hepatitis B virus; $\mathrm{HCV}$, hepatitis Cvirus; HIV, human immunodeficiency virus; ODT, opioid dependence treatment; SD, standard deviation. \# Patients could have more than one. * Comparison between groups (B/N and methadone) in monthly and $<1$ month frequency: $p$ value $\leq 0.001$

Design of the CRF and Patient Diary

A steering committee - consisting of the chairman of the Spanish Scientific Society for Studies on Alcohol, Alcoholism and Other Drug Addictions (Sociedad Científica Española de Estudios sobre el Alcohol, el Alcoholismo y las otras Toxicomanías, SOCIDROGALCOHOL), a university professor of social psychology, and the head of the department of health psychology of the Universidad Miguel Hernández - and a patient with OUD, collaborated with 2 experts in Health Outcomes Research to design the CRF and the patient diary. In addition, the patient with OUD participated in the adaptation of the language of the patient diary questions to facilitate understanding. To make diary completion as practical and simple as possible, all questions had fixed response options, and several Likert scales were also used. A continuous
Likert scale (1-10) was used to know the overall interest of patients in PRB, with 1 denoting the lowest and 10 the highest interest. Gradual Likert scales with 4 response options were used to know the degree of importance assigned to different characteristics associated with PRB that could lead patients to choose it as treatment - clustering the results by importance (" $n o t$ at all important" and "unimportant" vs. "important" and "very important") - what represented PRB for the patients, and the reasons why patients would not choose PRB as their ODT - clustering the results by degree of agreement ("not at all" and "not completely" vs. "quite a bit" and "yes, absolutely"). To know whether patients would be willing to switch from their current ODT to PRB, a gradual Likert scale with 5 options was used. The results were grouped based on the decision to change ("no, of course not" and "no, I 
think not" vs. "I cannot make that decision now" vs. "yes, maybe" and "yes, definitely").

\section{Study Endpoints}

The primary endpoint was to determine the proportion of patients in each treatment group ( $\mathrm{B} / \mathrm{N}$ or methadone) who would switch to PRB. Secondary objectives were to determine - also by treatment group - the sociodemographic characteristics, the rating of the PRB product, what PRB represented for them, the characteristics of PRB for which they would choose it as their ODT, opinion about the change, and the reasons why they would or would not switch to it.

\section{Secondary Outcomes}

Secondary analysis exploring if psychiatric or organic comorbidities would rate higher on willingness to change categories would be considered if the number of subjects per cell is above 5 .

\section{Statistical Analysis}

The sample size needed to estimate, with a precision of $10 \%$ and a confidence of $95 \%$, the proportion of patients who would be willing to switch treatment was calculated. This estimate is based on the Bendimerad et al. [27] study, where $53.2 \%$ of patients in treatment for OUD were willing to switch or modify their treatment. Based on these data, 96 patients would be needed, to which an additional $10 \%$ would be added for potential losses during the study, up to a total of 106 patients.

For the descriptive study, absolute and relative frequencies were calculated for qualitative variables, as well as the mean and standard deviation for quantitative variables, and the $95 \%$ confidence interval (95\% CI) for the result of the primary endpoint. For the inferential analysis comparing patients who had received methadone and B/N, Pearson's $\chi^{2}$ test and Fisher's exact test, if any requirement of the former was not met, were used for qualitative variables. Student's $t$ test was used for quantitative variables, assuming normality when there were $>30$ cases in each group. The type I error threshold used to accept or reject the null hypotheses was $5 \%$. Calculations were performed using R 4.0.4 software.

\section{Results}

\section{Study Population}

Of the 99 patients recruited in the 6 participating centres, 98 were analysed: $50 \%$ on methadone and the other $50 \%$ on $\mathrm{B} / \mathrm{N}$. One patient on naltrexone was excluded from the analysis because he did not meet the study inclusion criteria.

\section{Sociodemographic and Clinical Characteristics}

Table 1 shows the sociodemographic and clinical characteristics of patients included in the study analysis. The mean age was $46.9 \pm 8.4$ years, and $79.6 \%$ of participants were male. The $\mathrm{B} / \mathrm{N}$ group had a greater proportion of patients with children $(50.0 \%$ in the $\mathrm{B} / \mathrm{N}$ vs. $26.5 \%$ in the methadone group; $p=0.022)$ and lower HCV rates $(2.0 \%$ with $\mathrm{B} / \mathrm{N}$ vs. $22.5 \%$ with methadone; $p=0.002$ ) than patients on methadone. Patients with $\mathrm{B} / \mathrm{N}$ had received treatment for OUD for 6.3 years less than patients with methadone $(10.4 \pm 7.6$ vs. $16.7 \pm 9.3$ years, respectively; $p<0.001)$. These patients had also started their current ODT 5.1 years later than those on methadone $(4.6 \pm 4.2$ vs. $9.7 \pm 8.6$ years, respectively; $p<0.001)$. Most patients were in the maintenance phase for OUD $(85.7 \%$ with $\mathrm{B} / \mathrm{N}$ vs. $91.5 \%$ with methadone; $p=0.337$ ); the remaining patients were in the reduction phase (Table 1). All the sociodemographic and clinical characteristics can be found in online supplementary Table 1 (for all online suppl. material, see www.karger.com/doi/10.1159/000520091). With regard to the frequency of collecting the medication, a significantly lower proportion of patients collected their medication with a less-than-once-a-month frequency in the $\mathrm{B} / \mathrm{N}$ group than the methadone group ( $89.8 \%$ vs. $23.4 \%$, respectively; $p<0.001$ ). Most patients in the $\mathrm{B} / \mathrm{N}$ group $(42.6 \%)$ collected the medication monthly (Table 1).

\section{Primary Endpoint}

Approximately $65 \%$ of patients in each treatment group would be willing to change their current ODT for $\mathrm{PRB}, 63.3 \%$ (95\% CI 46.3-80.2) with $\mathrm{B} / \mathrm{N}$ and $65.3 \%$ (95\% CI: 48.8-81.7) with methadone, $p>0.833$ (Fig. 1). Of these, a significantly higher proportion of patients in the $\mathrm{B} / \mathrm{N}$ group considered that switching to PRB would be easy or very easy comparing to patients in the methadone group ( $90.3 \%$ vs. $46.9 \%$, respectively; $p<0.001)$. Moreover, almost twice as many patients in the $\mathrm{B} / \mathrm{N}$ group compared with those in the methadone group would be willing to switch from their current ODT to PRB once the product was available $(64.5 \%$ vs. $34.3 \%$, respectively; $p=$ 0.005) (data not shown). When patients were asked how often they would like to take PRB, most preferred the monthly dosing, regardless of the treatment group (100\% with $\mathrm{B} / \mathrm{N}$ vs. $93.6 \%$ with methadone; $p=0.514$ ) (Table 2 ).

\section{Rating of Product $X$}

The mean rating on the interest of patients in PRB of the total sample was 7.2 out of 10 . There was a similar rating across treatment groups, 7.4 in the $\mathrm{B} / \mathrm{N}$ group and 7.0 in the methadone group $(p=0.520)$ (Fig. 1).

Figure 2 shows the analysis of what PRB represented to patients by treatment group. The factors identified by a greater proportion of patients in the methadone group were "be able to feel better, improve my daily life and relations" (79.6\%), "be able to stay better/adhere to my treatment, thus avoiding withdrawal symptoms and relapses" 
Fig. 1. Percentage of patients who would switch from their current ODT to PRB. $\mathrm{B} / \mathrm{N}$, buprenorphine/naloxone; ODT, opioid dependence treatment; PRB, prolonged-release buprenorphine.

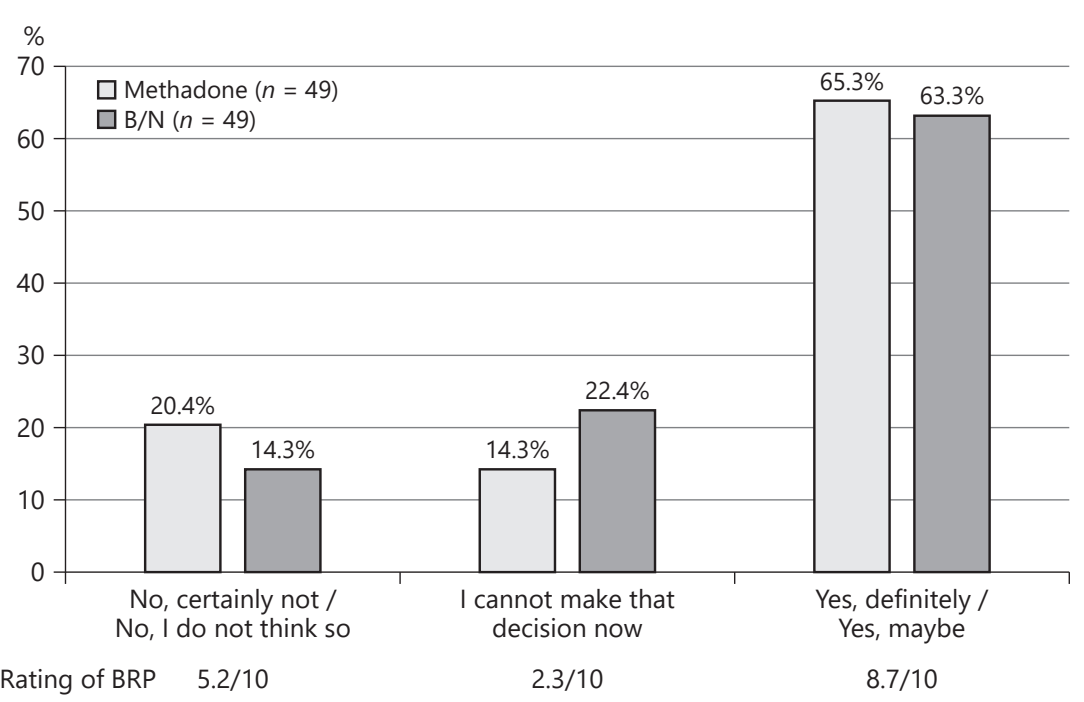

$2.3 / 10$

$8.7 / 10$

Table 2. Opinion of patients on the switch to PRB

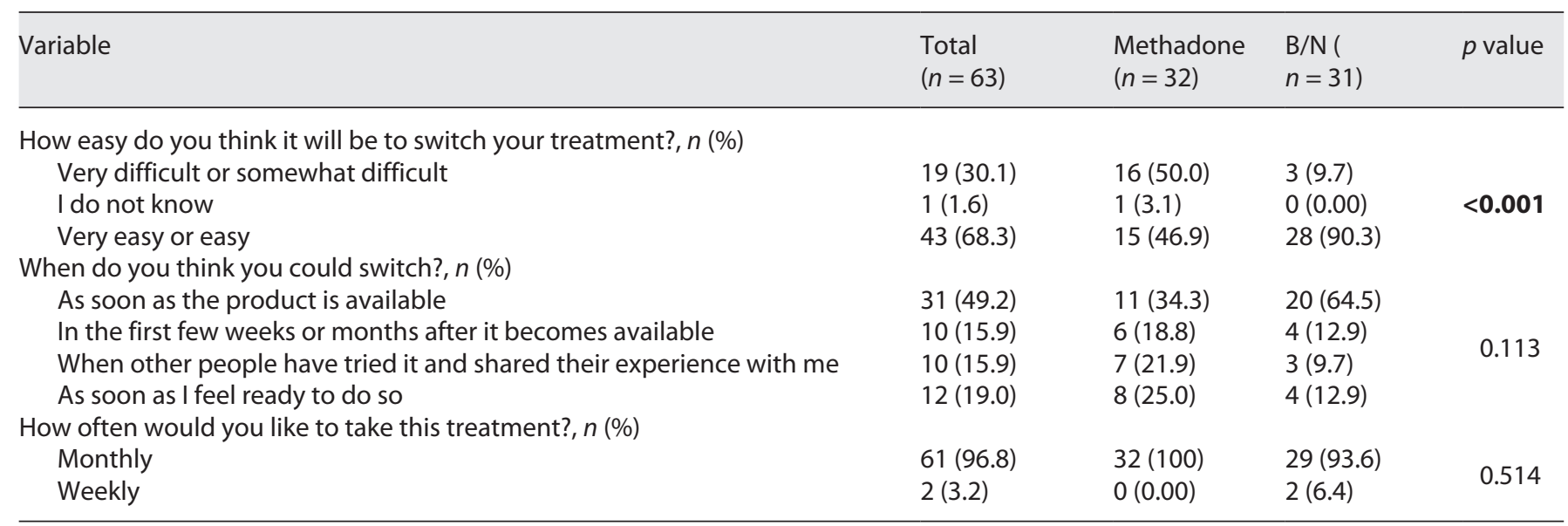

Attributes with $p<0.05$ are shown in bold. B/N, buprenorphine/naloxone; PRB, prolonged-release buprenorphine.

(77.6\%), and "less effort than current treatment" (77.6\%), while factors in group $\mathrm{B} / \mathrm{N}$ were "stabilizing with no need to remember daily that I have to take it" $(81.6 \%)$ and " $a$ novelty that is worth trying" (79.2\%). There were no statistically significant differences between the treatment groups.

When looking at the characteristics of PRB that could lead patients to choose it as their ODT, the 5 characteristics identified by a greater proportion of patients as " $i m$ portant" or "very important" were found to be the same for both treatment groups: "be sure to have a constant dose, always effective throughout the week or month" (85.7\% with $\mathrm{B} / \mathrm{N}$ vs. $83.7 \%$ with methadone), "the possibility of taking the medicine only once a week or once a month" ( $87.5 \%$ with B/N vs. $81.6 \%$ with methadone), "not having to take the medicine daily" ( $83.7 \%$ with $\mathrm{B} / \mathrm{N}$ vs. $79.6 \%$ with methadone), "the possibility of having a more convenient treatment (a weekly/monthly injection), compared to having to take the medication daily" (79.6\% with $\mathrm{B} / \mathrm{N}$ vs. $77.6 \%$ with methadone), and "not forgetting to take the medication" $(81.6 \%$ with $\mathrm{B} / \mathrm{N}$ vs. $75.5 \%$ with methadone) (Fig. 3). The assessment and importance of 


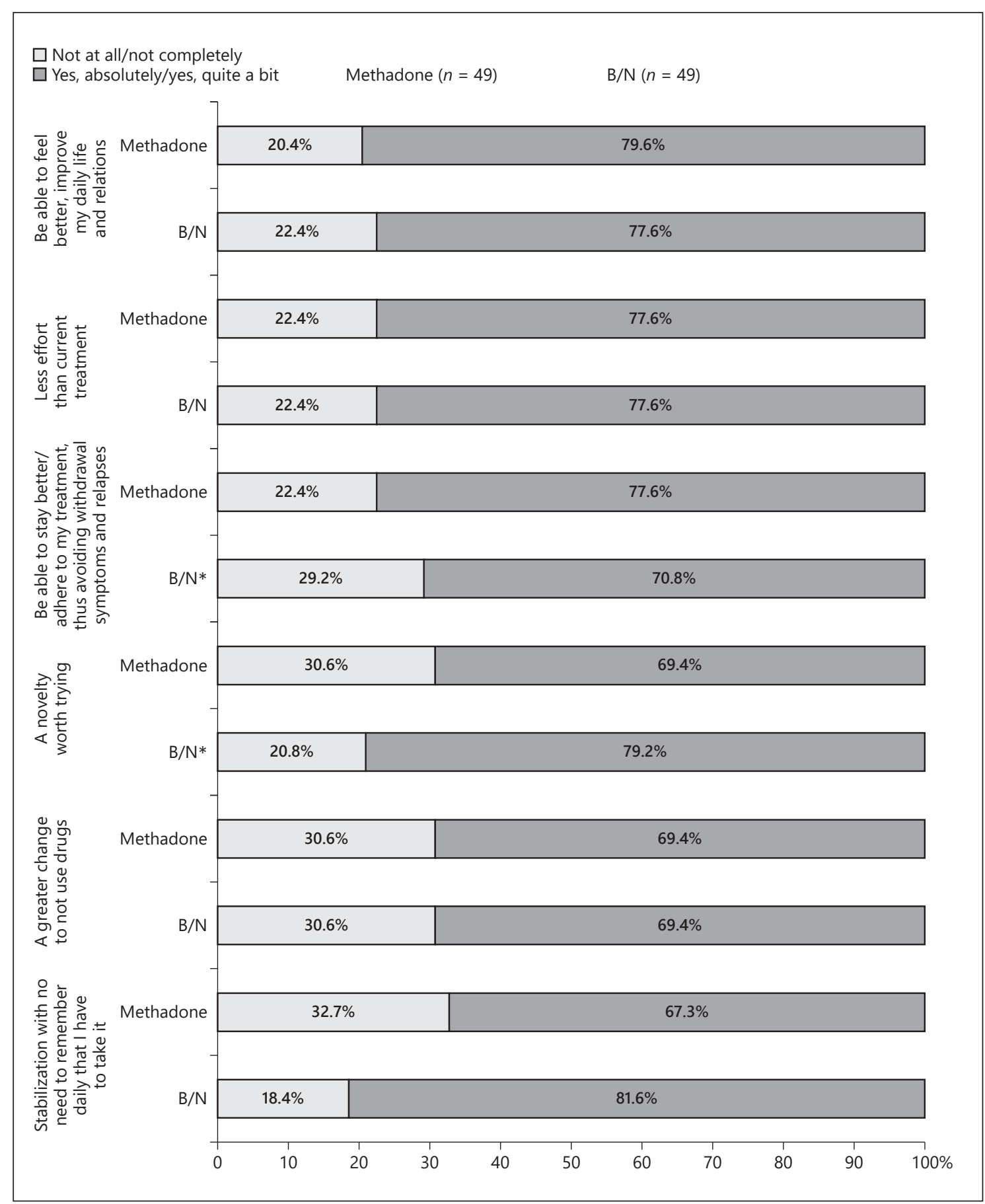

Fig. 2. What $\mathrm{PRB}$ represents for patients. ${ }^{*} 1$ missing value. $\mathrm{B} / \mathrm{N}$, buprenorphine/naloxone; $\mathrm{PRB}$, prolonged-release buprenorphine.

all the remaining characteristics of PRB are detailed in online supplementary Figure 1.

Figure 4 shows the reasons why patients would not switch from their current ODT to PRB. This was analysed in patients who answered that they would not be willing to switch from their ODT (7/49 [14.3\%] with B/N versus $10 / 49$ [20.4\%] with methadone) and in those who answered that they could not make that decision at that time 


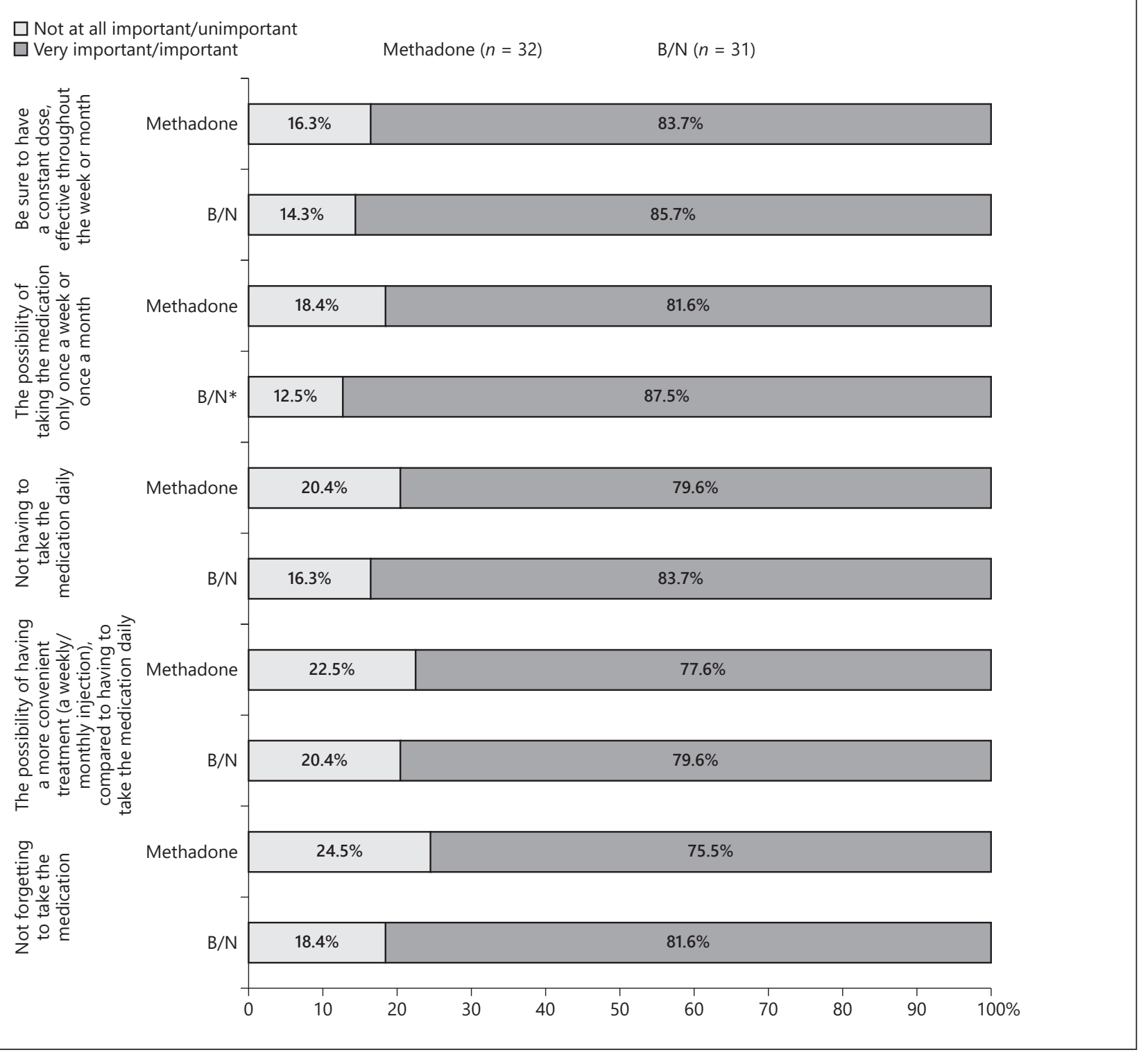

Fig. 3. Main characteristics of PRB that could lead to choosing it as ODT. * 1 missing value. B/N, buprenorphine/ naloxone; ODT, opioid dependence treatment; PRB, prolonged-release buprenorphine.

(11/49 [22.4\%] with $\mathrm{B} / \mathrm{N}$ versus $7 / 49$ [14.3\%] with methadone). The reason for not switching to PRB reported by a greater proportion of patients was the route of administration by injection. This was observed in both the $\mathrm{B} / \mathrm{N}$ group $(11 / 18,64.7 \%)$ and the methadone group $(5 / 17$, $29.4 \%)$, although with a significantly higher proportion in the $\mathrm{B} / \mathrm{N}$ group $(p=0.039)$. Another reason given by patients in the methadone group was that their experience with $\mathrm{B} / \mathrm{N}$ in the past had not been $\operatorname{good}(5 / 17,29.4 \%)$ (Fig. 4).

Patients Perception on a Prolonged-

Release Buprenorphine in OUD

\section{Discussion}

New formulations of PRB - with a pharmacological effect lasting a week or a month - may improve adherence and retention and prevent diversion [28], which would result in an effective and sustained dosing and decrease healthcare burden [29]. To our knowledge, there are few studies assessing the patient-reported therapeutic preference for or susceptibility to these new formulations of PRB injections by different treatment groups in people 
$\square$ Not at all/not completely

$\square$ Yes, absolutely/yes, quite a bit

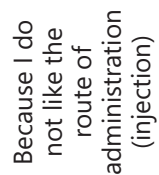

Methadone

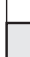

Me.6\%

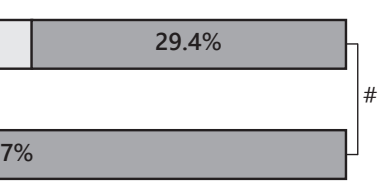

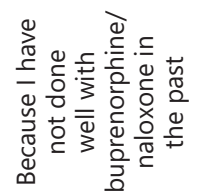

Methadone

$\mathrm{B} / \mathrm{N} *$

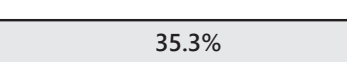

$70.6 \%$

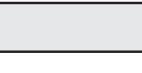

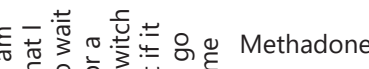

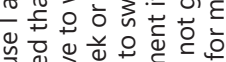

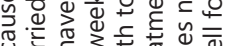

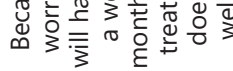

$\mathrm{B} / \mathrm{N} * *$

$70.6 \%$

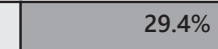

**

$93.8 \%$

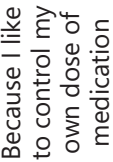

$\mathrm{B} / \mathrm{N}$

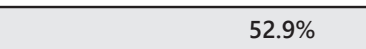

$23.5 \%$

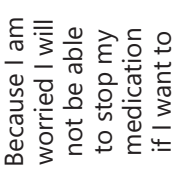

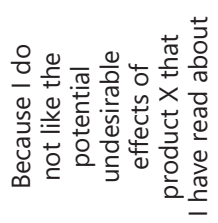

Methadone

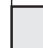

$23.5 \%$

$\mathrm{B} / \mathrm{N}^{*}$

$52.9 \%$

$47.1 \%$

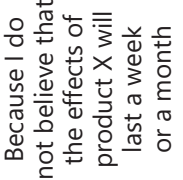

Methadone

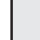

$6.5 \%$

$\mathrm{B} / \mathrm{N}^{*}$

$11.8 \%$

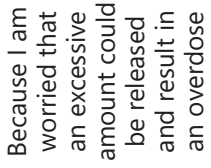

Methadone

$17.6 \%$

$\mathrm{B} / \mathrm{N}^{*}$

$82.4 \%$

$17.6 \%$

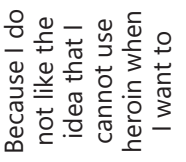

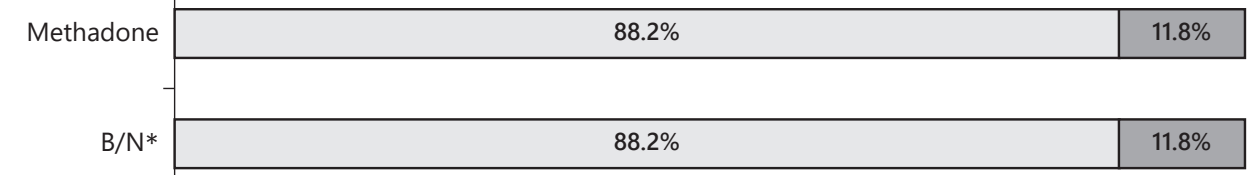

Methadone

$94.1 \%$

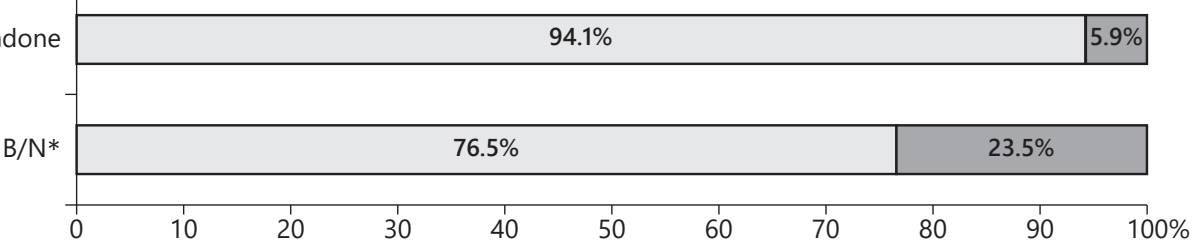

(For legend see next page.) 
with OUD. The PREDEPO study is the first to assess the preference for PRB depending on treatment group.

Data from the PREDEPO study show a high degree of acceptance for PRB injection as ODT. Two out of 3 patients - both in the total sample and in each treatment group - reported that they would be willing to switch from their current ODT to PRB, which also shows a good willingness to start PRB. Most patients also expressed a great interest (7.2 out of 10) for this new formulation. In addition, all patients who expressed a preference regarding frequency of administration stated that they would prefer monthly, rather than weekly, dosing. These data are in agreement with those reported in other studies about the perception of PRB by patients with OUD. In a French study on 357 patients, the mean interest in PRB was 6.2 out of 10 [30]. In another study conducted in Australia, $68 \%$ of the total sample $(n=402)$ thought that PRB would be a good treatment option for OUD, and $84.86 \%$ of patients who declared the preference on frequency of administration said that they would prefer the monthly administration [31].

Regarding sociodemographic and clinical characteristics, the statistically significant differences seen between the treatment groups may be explained by the nature of ODT itself. Patients on $\mathrm{B} / \mathrm{N}$ had greater family stability (having a significantly higher number of children) and significantly lower HCV rates. Patients on methadone have been treated for a longer time than $\mathrm{B} / \mathrm{N}$ patients on average, which was to be expected because $\mathrm{B} / \mathrm{N}$ was approved in Spain and started to be prescribed gradually from 2010 onwards. Meanwhile, prescription of methadone started in the 1980s. Moreover, with regard to the frequency of collecting the medication, methadone patients attend more frequently to collect their medication than patients on $\mathrm{B} / \mathrm{N}$.

No statistically significant differences were seen between treatment groups in the interest in or the perception of PRB. However, most patients in the methadone group perceived $\mathrm{PRB}$ as a more promising treatment around personal well-being, which would require less effort than the current ODT in terms of administration and collecting the medication, thus improving their life and relations. On the other hand, patients on $\mathrm{B} / \mathrm{N}$ perceived PRB as a novel treatment worth trying that would avoid having to think about daily administration. These data

Fig. 4. Reasons why patients would not switch from their current ODT to PRB. ${ }^{*} p=0.039 .{ }^{*} 1$ missing value; ${ }^{* *} 2$ missing values. $\mathrm{B} / \mathrm{N}$, buprenorphine/naloxone; ODT, opioid dependence treatment; $\mathrm{PRB}$, prolonged-release buprenorphine.

Patients Perception on a Prolonged-

Release Buprenorphine in OUD are similar to those reported in several studies, where patients stated that prolonged-release treatments could facilitate life, reduce stigma, and free up time for their personal and professional life as they would have to collect medication less frequently $[18,31]$.

After analysing the reasons why patients would choose PRB as ODT, no significant differences were found between the groups. The reasons that could lead to switching treatment stated by more patients in both groups were those related to the lower frequency of administration taking a medicine at a constant dose and with sustained efficacy, taking the medication once monthly or weekly instead of daily, and not forgetting to take the medication.

However, patients on $\mathrm{B} / \mathrm{N}$ were more prone to a treatment switch as approximately $90 \%$ of them would consider switching to PRB very easy or easy, more than double as compared to patients on methadone $(p<0.001)$. In addition, most of them would do so as soon as it became available. This may be explained by their previous experience with $\mathrm{B} / \mathrm{N}[32$ ] and the more spaced administration over time as compared to methadone, which would allow for conciliation of their work and personal activities with treatment [33].

Only $18 / 49$ (36.7\%) and $17 / 49$ (34.7\%) patients in the $\mathrm{B} / \mathrm{N}$ and methadone group, respectively, would not switch treatment. Of these, approximately $15 \%$ of patients in both groups stated that they were not able to make the decision at the time of the survey. The reason why a greater proportion of patients reported that they did not want to switch to PRB was that the route of administration was an injection. This may be explained by the lack of patients' experience with PRB. In this regard, providing patients with enough information and adequate education about the treatment is essential to give them a better understanding of the characteristics of PRB, in order to help them make a fully informed choice about their ODT. Thus, it is important that patients know that the frequency of injection site reactions are low, and most are mild to moderate $[34,35]$. Patients should also be informed about the potential benefits of PRB, such as avoidance of the need for daily dosing, reduction of regular visits to the centre, and risks of accidental exposure [18, 34, 36-38].

While current ODTs are effective for managing OUD $[9,11,14]$, treatment adherence is low, and treatment discontinuation is usually common [22]. This may be explained by the barriers related to treatments as they are associated with frequent dosing, difficulty in achieving optimal dosage, misuse, diversion, and the stigma associated with treatment [18]. Although there is little pub-

Eur Addict Res 2022;28:143-154 151 
lished evidence, shared decision-making between the patient and the clinician may improve adherence in patients in drug treatment programs [39]. In this regard, many patients demand less frequent dosing of treatment, which provides greater flexibility in dosing and duration, thus allowing for more time and freedom to normalize both personal and professional life [19-21, 40]. These findings were similar to those of a recent study, performed in subjects from 7 different countries, evaluating patient-reported experience measures in patients treated with PRB [34]. A total of $83 \%$ of patients who switched from SL BPN reported that PRB was better than their previous treatment. Patients also rated some of the characteristics regarding treatment with BPN such as ease of travel, daily adherence, privacy, lack of need for daily medication or regular visits to the pharmacy, and no accidental exposure of children, among others. In all these measures, median scores for patient's satisfaction with $\mathrm{PRB}$ at 6 and 12 months were of 7 (i.e., "extremely important").

Strengths of this study include the fact that it was conducted in a context of real-world evidence and on a representative geographic sample including 6 different Spanish regions (autonomous communities). On the other hand, this project has some limitations that should be taken into account when interpreting the results. It is possible that more motivated patients would have more likely to participate and that this could have been a potential bias. This selection bias may explain the high rate of acceptability of treatment switch in both groups. In addition, it is worth mentioning that all aspects related to the prescription modality (collecting the medication with a higher frequency, co-payment of the treatment, etc.) that could increase the burden of treatment and influence the willingness to switch were not collected in this study. Although the estimated sample size to determine the primary objective was reached, no significant differences were seen between the treatment groups in some of the comparisons analysed. This may be because for questions about preferences, a sub-analysis was performed only in patients who answered in a certain way in some questions, and therefore, the entire sample was not included. This may be observed, for instance, in the question about the reasons why patients would not switch to $\mathrm{PRB}$, where the number of responders is 18 with $\mathrm{B} / \mathrm{N}$ and 17 with methadone. A secondary analysis on willingness to change according to psychiatric or organic comorbidities could not be performed because of a lack of power. Moreover, patients were not randomly selected, which would have provided more pieces of evidence to the study re- sults. Consecutive selection was decided to facilitate data collection due to the different periods of medication collection and the emergency situation derived from the COVID-19 pandemic.

\section{Conclusion}

Patients included in this study and treated with ODT for OUD showed a high acceptance of a treatment switch to PRB. Two out of 3 patients declared that they would switch treatment, with a rating of $\mathrm{PRB}$ of 7 out of 10 . Most patients stated that they would prefer monthly administration. These results were similar in both treatment groups. More than $90 \%$ of patients treated with $\mathrm{B} / \mathrm{N}$ considered that switching to PRB would be easy. Patients currently under methadone treatment express more fears that switching will be more difficult, although they do not declare less frequently that they are willing to switch. The reasons why patients would switch to this new formulation include administration of a constant dose with sustained efficacy, with a non-daily dosing that would prevent the possibility of forgetting intake of medication. Only a low proportion of patients would not switch treatment to PRB, and the main reason was the route of administration by subcutaneous injection. These results suggest that PRB may play a significant role in the current therapeutic framework for OUD as its greater dosing flexibility and duration of action would decrease the high burden of care. This would also reduce the associated stigma, allowing more time and freedom to normalize both the personal and professional lives of patients while avoiding misuse and diversion of medication.

\section{Acknowledgments}

The authors thank Ruth Olmos and Hugo López for their participation in organizing the start of the study, and José Joaquín Mira and Miguel Velázquez Gorsse for their participation and collaboration in the study design.

\section{Statement of Ethics}

The PREDEPO study was approved by the Research Ethics Committee of Euskadi (Basque Country, Spain) (code: PI2020149) and was conducted in accordance with the principles of the Declaration of Helsinki regarding medical research in human subjects. All subjects gave written informed consent to participate in the study. 


\section{Conflict of Interest Statement}

Álvaro Muñoz, Manuel Gómez, and Miguel Ángel Casado are employed by PORIB, a consultant company specializing in the economic evaluation of health interventions, which received financial support from Camurus S.L. for the development of the study design, data analysis, and drafting of the manuscript. Rodrigo Oraa, Gerardo Flórez, Pilar Notario, Pedro Seijo, Begoña Gonzalvo, and Francisco Salvador Pascualdeclare that they have no conflicts of interest. Carla Assaf is employed by Camurus S.L, Spain.

\section{Funding Sources}

This work was sponsored by Camurus S.L.

\section{Author Contributions}

Francisco Salvador Pascual contributed to literature search, study design, data collection, data interpretation, writing, and critical review. Rodrigo Oraa; Gerardo Flórez; Pilar Notario; Pedro Seijo; Begoña Gonzalvo contributed to literature search, data collection, data interpretation, writing, and critical review. Álvaro Muñoz; Manuel Gómez; Miguel Ángel Casado contributed to literature search, study design, data analysis, data interpretation, writing, and critical review. Carla Assaf involved in data interpretation, writing, and critical review.

\section{Data Availability Statement}

All data generated or analysed during this study are included in this article and its online supplementary material files. Further enquiries can be directed to the corresponding author.

\section{References}

1 World Health Organization. Information sheet on opioid overdose. 2018. [WWW Document] [cited 2021 Mar 16]. Available from: https://www.who.int/substance_abuse/information-sheet/en/.

2 EMCDDA. European drug report 2020: trends and developments. 2020. [cited 2021 March 16]. Available from: https://www. emcdda.europa.eu/system/files/publications/6343/20174796_TD0117699ESN_PDF. pdf.

3 Degenhardt L, Whiteford HA, Ferrari AJ, Baxter AJ, Charlson FJ, Hall WD, et al. Global burden of disease attributable to illicit drug use and dependence: findings from the Global Burden of Disease Study 2010. Lancet. 2013 Nov 9;382(9904):1564-74.

4 González-Saiz F, Lozano Rojas ÓM, Martín Esteban J, Bilbao Acedos I, Ballesta Gómez R, Gutiérrez Ortega J. Psychiatric comorbidity in a sample of opiate-dependent patients treated with sublingual buprenorphine in a therapeutic community regime. Rev Psiquiatr Salud Ment. 2011 Apr;4(2):81-7.

5 Roncero C, Fuster D, Palma-Álvarez RF, Rodriguez-Cintas L, Martinez-Luna N, Álvarez FJ. HIV and HCV infection among opiatedependent patients and methadone doses: the PROTEUS study. AIDS Care. 2017 Dec; 29(12):1551-6.

6 Roncero C, Barral C, Rodríguez-Cintas L, Pérez-Pazos J, Martinez-Luna N, Casas M, et al. Psychiatric comorbidities in opioid-dependent patients undergoing a replacement therapy programme in Spain: the PROTEUS study. Psychiatry Res. 2016 Sep 30;243:17481.
7 Canadian Agency for Drugs and Technologies in Health. Rapid response reports. Suboxone $^{\circ}$ versus methadone for the treatment of opioid dependence: a review of the clinical and cost-effectiveness. 2013. [cited 2021 Mar 16]. Available from: http://www.ncbi.nlm. nih.gov/books/NBK195153/.

8 Bell J, Strang J. Medication treatment of opioid use disorder. Biol Psychiatry. 2020 Jan 1; 87(1):82-8.

9 Dematteis M, Auriacombe M, D’Agnone O, Somaini L, Szerman N, Littlewood R, et al. Recommendations for buprenorphine and methadone therapy in opioid use disorder: a European consensus. Expert Opin Pharmacother. 2017 Dec;18(18):1987-99.

10 Roncero C, Domínguez-Hernández R, Díaz T, Fernández JM, Forcada R, Martínez JM, et al. Management of opioid-dependent patients: comparison of the cost associated with use of buprenorphine/naloxone or methadone, and their interactions with concomitant treatments for infectious or psychiatric comorbidities. Adicciones. 2015 Sep 15;27(3): $179-89$.

11 Connery HS. Medication-assisted treatment of opioid use disorder: review of the evidence and future directions. Harv Rev Psychiatry. 2015 Mar-Apr;23(2):63-75.

12 Mattick RP, Kimber J, Breen C, Davoli M. Buprenorphine maintenance versus placebo or methadone maintenance for opioid dependence. Cochrane Database Syst Rev. 2004;3: CD002207.

13 Volkow ND, Frieden TR, Hyde PS, Cha SS Medication-assisted therapies: tackling the opioid-overdose epidemic. N Engl J Med. 2014 May 29;370(22):2063-6.

14 Sordo L, Barrio G, Bravo MJ, Indave BI, Degenhardt L, Wiessing L, et al. Mortality risk during and after opioid substitution treatment: systematic review and meta-analysis of cohort studies. BMJ. 2017 Apr 26;357:j1550.
15 Gowing L, Farrell MF, Bornemann R, Sullivan LE, Ali R. Oral substitution treatment of injecting opioid users for prevention of HIV infection. Cochrane Database Syst Rev. 2011 Aug 10(8):CD004145.

16 Bukten A, Skurtveit S, Gossop M, Waal H, Stangeland P, Havnes I, et al. Engagement with opioid maintenance treatment and reductions in crime: a longitudinal national cohort study. Addiction. 2012 Feb;107(2):3939.

17 Strang J, Groshkova T, Uchtenhagen A, van den Brink W, Haasen C, Schechter MT, et al. Heroin on trial: systematic review and metaanalysis of randomised trials of diamorphineprescribing as treatment for refractory heroin addiction. Br J Psychiatry. 2015 Jul;207(1): 5-14.

18 Gilman M, Li L, Hudson K, Lumley T, Myers $\mathrm{G}$, Corte C, et al. Current and future options for opioid use disorder: a survey assessing real-world opinion of service users on novel therapies including depot formulations of buprenorphine. Patient Prefer Adherence. 2018 Oct 11;12:2123-9.

19 Harris J, McElrath K. Methadone as social control: institutionalized stigma and the prospect of recovery. Qual Health Res. 2012 Jun; 22(6):810-24.

20 Treloar C, Valentine K. Examining structural violence in opioid pharmacotherapy treatment in Australia: sweating the "small stuff" in a liberal paradise. Int J Drug Policy. 2013 Nov;24(6):e11-3.

21 Neale J, Tompkins CNE, McDonald R, Strang J. Patient views of opioid pharmacotherapy biodelivery systems: qualitative study to assist treatment decision making. Exp Clin Psychopharmacol. 2018 Dec;26(6):570-81.
Patients Perception on a ProlongedRelease Buprenorphine in OUD
Eur Addict Res 2022;28:143-154 
22 Strang J, Reed K, Bogdanowicz K, Bell J, van der Waal R, Keen J, et al. Randomised comparison of a novel buprenorphine oral lyophilisate versus existing buprenorphine sublingual tablets in opioid-dependent patients: a first-in-patient phase II randomised open label safety study. Eur Addict Res. 2017;23(2): 61-70.

23 Sigmon SC, Moody DE, Nuwayser ES, Bigelow GE. An injection depot formulation of buprenorphine: extended bio-delivery and effects. Addiction. 2006 Mar;101(3):420-32.

24 Sigmon SC, Bigelow GE. Food and Drug Administration approval of sustained-release buprenorphine for treatment of opioid dependence: realizing its potential. Addiction. 2017 Mar;112(3):386-7.

25 Vorspan F, Hjelmström P, Simon N, Benyamina A, Dervaux A, Brousse G, et al. What place for prolonged-release buprenorphine depotformulation Buvidal ${ }^{\oplus}$ in the treatment arsenal of opioid dependence? Insights from the French experience on buprenorphine. Expert Opin Drug Deliv. 2019 Sep;16(9):907-14.

26 Battle DE. Diagnostic and statistical manual of mental disorders (DSM). Codas. 2013; 25(2):191-2.

27 Bendimerad P, Kosim M, Trojak B. Patient acceptance and acceptability of a new longacting form of buprenorphine: AMBRE survey results. Poster presented at the ATHS Conference. France: Biarritz; 2019 Oct 1-4.

28 Kenney SR, Anderson BJ, Bailey GL, Stein $\mathrm{MD}$. Buprenorphine treatment formulations: preferences among persons in opioid withdrawal management. J Subst Abuse Treat. 2018 Nov;94:55-9.
29 Rosenthal RN, Goradia VV. Advances in the delivery of buprenorphine for opioid dependence. Drug Des Devel Ther. 2017 Aug 28;11: 2493-505.

30 Rolland B, Trojak B, Nourredine M, Bachellier J, Chappuy M, Bendimerad P, et al. Determinants of interest in extended-released buprenorphine: a survey among 366 French patients treated with buprenorphine or methadone. Drug Alcohol Depend. $2021 \mathrm{Mar}$ 1;220:108492.

31 Larance B, Degenhardt L, Grebely J, Nielsen S, Bruno R, Dietze P, et al. Perceptions of extended-release buprenorphine injections for opioid use disorder among people who regularly use opioids in Australia. Addiction. 2020 Jul;115(7):1295-305.

32 Uebelacker LA, Bailey G, Herman D, Anderson B, Stein M. Patients' beliefs about medications are associated with stated preference for methadone, buprenorphine, naltrexone, or no medication-assisted therapy following inpatient opioid detoxification. J Subst Abuse Treat. 2016 Jul; 66:48-53.

33 Pereiro C, Fernández JJ. Guía de adicciones para especialistas en formación. Valencia: Socidrogalcohol; 2018. [WWW Document] [cited 2021 Mar 16]. Available from: https:// socidrogalcohol.org/wp-content/Pdf/publicaciones/manuales-guias/guia-adiccionespara-especialistas.pdf.
34 Frost M, Bailey GL, Lintzeris N, Strang J, Dunlop A, Nunes EV, et al. Long-term safety of a weekly and monthly subcutaneous buprenorphine depot (CAM2038) in the treatment of adult out-patients with opioid use disorder. Addiction. 2019 Aug;114(8):141626.

35 Lofwall MR, Walsh SL, Nunes EV, Bailey GL, Sigmon SC, Kampman KM, et al. Weekly and monthly subcutaneous buprenorphine depot formulations vs daily sublingual buprenorphine with naloxone for treatment of opioid use disorder: a randomized clinical trial. JAMA Intern Med. 2018 Jun 1;178(6):764-73.

36 Benyamina A, Stöver H. Barriers to treatment access and informed patient choice in the treatment of opioid dependence in Europe. Heroin Addict Relat Clin Probl. 2012;14:6580.

37 Rosenthal RN. Novel formulations of buprenorphine for treatment of opioid use disorder. Focus (Am Psychiatr Publ). 2019 Apr; 17(2):104-9.

38 Vecchio S, Ramella R, Drago A, Carraro D, Littlewood R, Somaini L. COVID19 pandemic and people with opioid use disorder: innovation to reduce risk. Psychiatry Res. $2020 \mathrm{Jul}$; 289:113047.

39 Joosten EA, de Jong CA, de Weert-van Oene GH, Sensky T, van der Staak CP. Shared decision-making reduces drug use and psychiatric severity in substance-dependent patients. Psychother Psychosom. 2009;78(4):245-53.

40 Tompkins CNE, Neale J, Strang J. Opioid users' willingness to receive prolonged-release buprenorphine depot injections for opioid use disorder. J Subst Abuse Treat. 2019 Sep; 104:64-71. 